\title{
PEATS RIDGE: a sandy track, citrus farms, springs, valleys, dams and the politics of ground water
}

\author{
Transforming Cultures eJ ournal, \\ Vol. 1 No. 2, J une 2006 \\ http:// epress.lib.uts.edu.au/journals/TfC
}

\author{
Trish FitzSimons \\ Griffith Film School \\ Griffith University, QLD
}

\begin{abstract}
This piece of writing is part of an exploration of 'the personal voice' within a Doctorate of Creative Arts. I come to this degree with a background as a documentary filmmaker and oral historian and with recent experience in the curation of a social history exhibition. My dissertation is entitled "Braided Channels: Reflections on the 'Voice of Documentary' from a cross media and inter disciplinary perspective.” The doctorate uses and examines several modes of address and definitions of communicative voice in order to extend our knowledge of how discourses can be delivered in a range of modes and media to engender a sense of veracity in the 'audience'.
\end{abstract}

In this essay I apply the quintessential documentary practice of metonymy to the medium of non- fiction writing, as a way to get to broader issues through individual example and personal experience. This paper then is a personal account of the uses of land and water on the Hawkesbury Sandstone ridge I lived on as a child and a consideration of how and why these patterns are shifting. This remembering has been motivated by current debates about water use, especially as it relates to bottled water coming from underground aquifers, alternatives to dam storage as the source of urban water supplies and the zoning of arable land adjacent to a growing city. I write in the spirit in which Katrina Proust of the ANU's Centre for Resource and Environmental Studies notes that environmental history can be a valuable tool in planning for the sustainable future use of a resource. This style of 'personal memoir meets environmental history' has of course antecedents not only in documentary film but also in print based work. One example of such work is the collection Landscapes of the Heart: Narratives of Nature and Self, edited by Michael Aleksiuk and came out of the University of Alberta in 2002.

Night...a thick cold causes disrupted sleep, a hawking cough and a great thirst for moisture. Dreams come fast, broken by waking up to cough and to sip water - suddenly, I am walking down a bush track that I know well. But it doesn't look the way I remember it. It is edged by gutters, houses and swimming pools, rather than the banksias and scribbly 
barked gums. In the dream I am panicked by a landscape I know and love looking barely recognizable. By day, the images have faded into fragments. But I know that track, even though it's more than thirty years since I lived, day by day, at one end of it.

The track joined the dry scrubby Hawkesbury sandstone ridge - on which my parents grew citrus and vegetables - to the deep lush valleys below and beyond. It was made by Italian workers in the early 1960's, as an aid to building the huge electricity stanchions from which were slung the power cables that created a cross cutting grid to and from the parallel ridges and valleys and on to the coastal towns of Gosford and Woy Woy beyond. The Italians would pass my family's farm each morning on the back of battered trucks, singing operas on their dawn forays down into the valley.

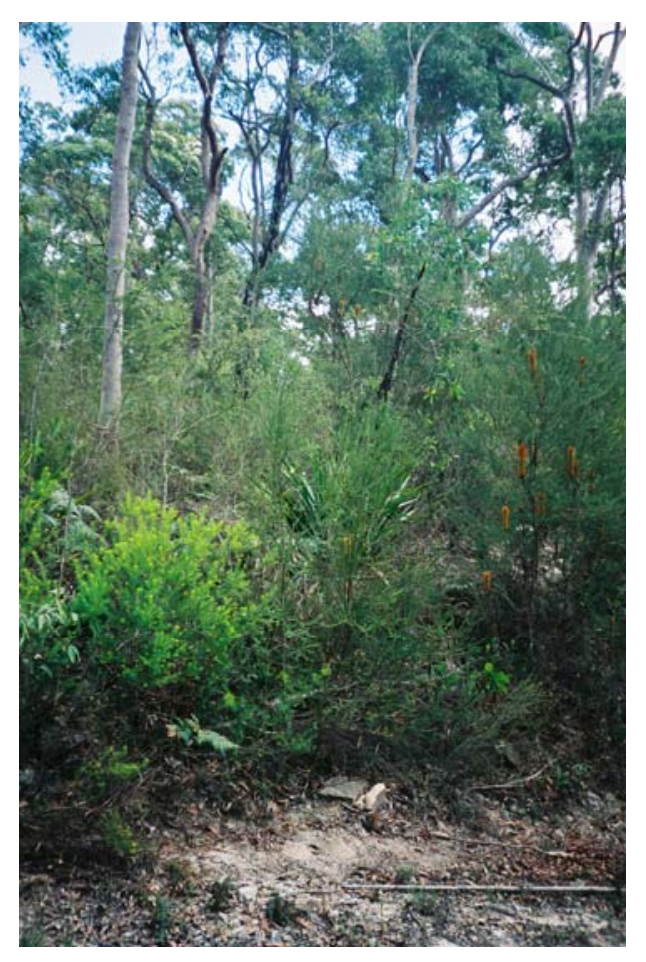

In my dream there was only one track, sliding into an endless vortex. In my childhood, there were many tracks, each a record of another incursion into the wild valley below my parent's farm. The building of water pipes, a municipal dam and the power lines, along with the excursions of weekend trail-bike riders, had each in turn created a network of rough and often eroded tracks through this bush, most of them eventually snaking their way from the scrubby ridges to the rich alluvial soil of the valleys, replete with creeks, waterfalls and rainforest.

\section{Peats Ridge Sandstone Scrub ${ }^{1}$}

Our ridge was a narrow one, its central spine roughly parallel to farming ridges on either side, with wild bush valleys separating the high ground. The farms and shelters of 'The Ridge' were slung loosely along this spine and the largely dead end roads that headed out from it ending in bush. Where the farms and dirt roads ended the rough bush tracks often began. Our farm was at the end of one such dirt

\footnotetext{
${ }^{1}$ All photographs in this paper have been taken by Cathy Morrison unless indicated otherwise.
} 
road, named for the neighbour that had made a living for decades as owner of the grader that formed and maintained the area's various sandy tracks.

Our neighbours were largely a microcosm of post war migrant Australia - Greeks and Italians and Finns and Turks and Cypriots - for whom a patch of cheap land and a chance to eke a living from it was preferable to the alternative of work in the burgeoning factories and public works. Nevertheless, the Sunday School and the P\&C, the tennis club and the community group continued to be dominated by Anglo families who had colonized the richest portions of the ridges a couple of generations before. These older established farms had deep free draining soil, more or less permanent springs and naturally grew tall trees and mountain lilies beside their water courses. My parents were themselves post war latecomers, but were soon accepted as part of the latter community. A repatriation scheme allowed my father to trade in his pre war office job for a position that taught him the rudiments of orcharding, deferred wages from the army gave him the cash to buy the land. But like other newcomers, my parents had to make do with the poorer sections of 'the ridge', generally rough scrub country right at the top and swampy grasslands on the gently sloping plateaus before the steep valley began. A 'drain every chain' became my father's motto to turn his land into farmland, as he set out digging ditches through the sandstone and conglomerate by hand, blasting with gelignite only when his manual labour alone was not equal to the task.

Our nearest neighbours on the Sydney side were the Fildissis family - two brothers who had recently migrated from Greece and their wives and children - who raised chickens and ran a small shop selling cracked eggs and local produce. On the Newcastle side lived the Bagalas and the Romolos - recent arrivals from Italy - who grew vegetables and raised pigs. On a track at the very end of the Ridge lived the Paces and the Freni-Cullalas, two families sharing the one house after arriving in Australia from Italy. In a school where every child was most obviously valuable in terms of retaining the vital second teacher, I well remember them arriving, the multiple children leading to a collective sigh of relief that the infant teacher's position was safe. Briefly their difference from us was marked by the lack of even a single English word between them, but before long they had entered into the world of Aussie English surrounding us. Of all the Pace kids, Guiseppe stands out in my 
mind, for his cheeky grin and ready adoption of Aussie customs. He morphed rapidly from the Southern Italian Guiseppe to the Aussie boy, Joe.

For Joe and for many of we local kids, the valleys were a kind of wonderland, a counterpoint to the responsibility and labour associated with life on the ridges.

By channels of coolness the echoes are calling,

And down the dim gorges I hear the creek falling.

(“Bellbirds” by Henry Kendall.)

This was Henry Kendall bellbird country: the scrubby wildflower rich ridge country gave way by degrees to the ferns and tree ferns and the 'moss and the sedges' of remnant rainforest pockets. Water was much more in evidence here than up on the ridges: in creeks and soaks and waterfalls. Way down in the bottom of the valley Mooney Creek, a tributary of the Hawkesbury, had been dammed to create Mooney Dam, part of the municipal water supply for Gosford, two ridges away.

These valleys were our playground and a landscape of our imagination besides. We would head down to explore the valleys in pairs or small groups, exhorted by our parents to use sticks to form arrows to mark the way we had taken amidst the morass of tracks. After a 'wet spell' we could hear the waterfalls and creeks of the valley below roaring with the rush

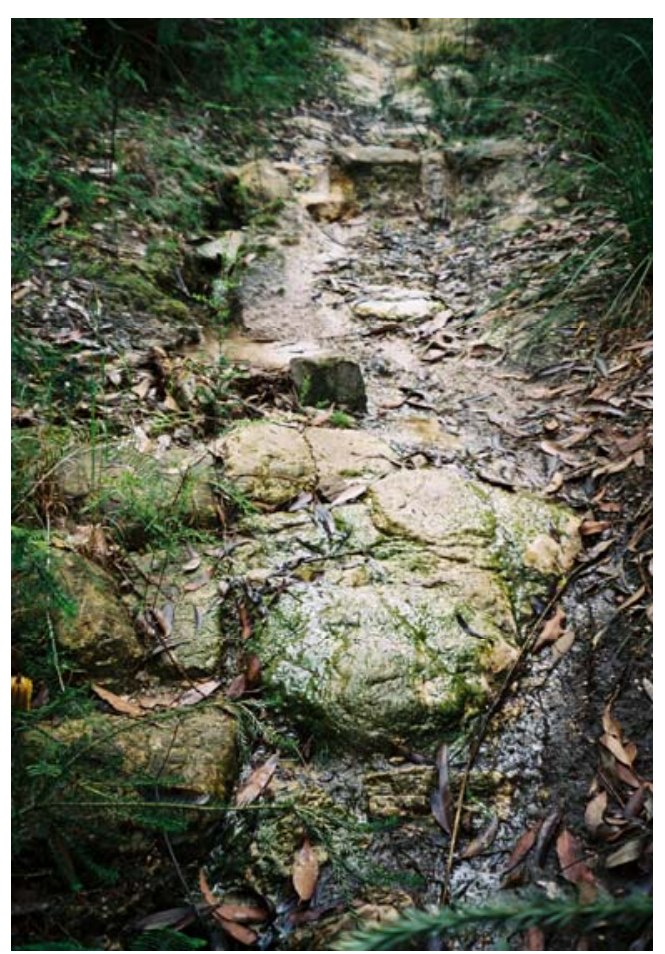

Water on eroded sandstone track. of water. It was a sound that called us to explore further at the earliest opportunity.

The springs that tended to be found in the first fall away from the ridge top were the exception to the rule of dry ridges and moist valleys that applied to all but the very best of the Ridge's farming country. Farming the poor sandy or swampy soil of the ridges was a difficult occupation that would have been nigh impossible without water storage and irrigation. Most blocks had a 'spring' somewhere, a precious piece of land where the 
Hawkesbury sandstone let a load of cool filtered water bubble naturally to the surface. Dammed, and combined with the seasonal rains, a farming family could manage its water to ensure that their plants grew well enough.

Some blocks had good springs, others not so good, but all but the poorest blocks had spring fed dams of some sort. As children this was the accepted order of the universe that we never thought anything of, other than it being vital knowledge when out walking on a hot and thirsty day.

On our farm the only good spring lay in the farthest corner of our land, right on the border with a neighbour. This spring, as well as rainfall, fed a large dam. Because that neighbour worked in the local basalt quarry rather than farming for a living (and therefore made very little call on the shared water) this was a workable arrangement. My father however always nursed an underlying fear that there could come a time when the neighbour might want to farm the land and that then, sharing the water of the spring fed dam across two farms could prove very difficult. Each year he added to the height of the dam's concrete spillway to add to total storage, and whenever possible increased the total size of the dam depression, as a guard against the consequences of such an eventuality. Our family's tennis court was made from clay that Dad dug out from the dam, in this way further expanding our water storage whilst adding another dimension to our lives. For those rare occasions when massive rain resulted in the dam being full to overflowing it had a built in valve that could be opened so that water could escape safely rather than risking have the dam's wall give way and lose all storage.

Whilst natural rainfall was the main source of moisture to our orchards and vegetable cash crops, irrigation from the dam in a dry period was a vital but limited supplement to my parent's farming. An old Lister engine, capable of making a noise resembling a jet engine when in full flight, pumped water up through pipes laid by my father all across our land. Only he had the strength to get the engine going and in the hot summer months he would supervise us swimming whilst he kicked the beast into life. And if he didn’t need to turn the pump on or off he could still be persuaded to take us swimming in the dam if we cooked a cake and made a thermos of hot milky tea or if we filled a trailer with small rocks that left 
the arable land easier to plough and added to the materials he had to work with in building up the spillway. A flying fox on metal rope strung across the widest expanse of the dam cemented our pleasure in this stored water. Because of the dangers associated with dam swimming we were forbidden to go to this dam on our own until well into adolescence. My parents made a point of always driving there, so that the thought of walking there on our own was less likely to occur to us. The story of Jeffrey, a boy from my primary school who died trying to swim a heavy rope across a dam by attaching it to his leg until the weight of waterlogged hemp dragged him under, made us know that the danger could be real.

Our dam was surrounded by the naturally occurring scrubby bush, which prevented any agricultural run-off that could otherwise have allowed the growth of algae. If any hint of nutrient bloom was seen my father would use the valve mentioned above to empty the dam in the midst of a good season, let the sun kill off all algal spores and then start the process of storage again, secure in the knowledge that the spring would assist in filling the dam before too long.

As well as irrigating the orchards and vegetables, dam water was pumped into an overhead tank and provided most of the water for the house, for toilets and for washing both clothes and bodies. Only one tap in the house - the cold water in the kitchen - came from the rainwater tank and woe betide anyone who left it running unnecessarily. Only a low pressure trickle came from the shower, so baths were the main way we washed. Baths were small, topped up with a modicum of fresh hot water as multiple occupants, in sequence or together went through their ablutions until my father with his body dirty from working the land came last. My mother recycled the washing water from load to load in her twin tub machine, coming last to my father's work clothes, the grey and greasy water emitting from these impossible to consider for reuse. Watering the garden was generally impossible, so drought resistant garden plants and brown lawns whenever rain had been scarce were entirely normal. The exception was our back garden, where water and nutrients from the septic system supported a lush growth of camellias and violets, maidenhair fern and strawberries.

Years passed, I went to boarding school and university in the city, my parents died, I 
moved interstate, had children of my own and set up a life in suburbia. The dam and spring

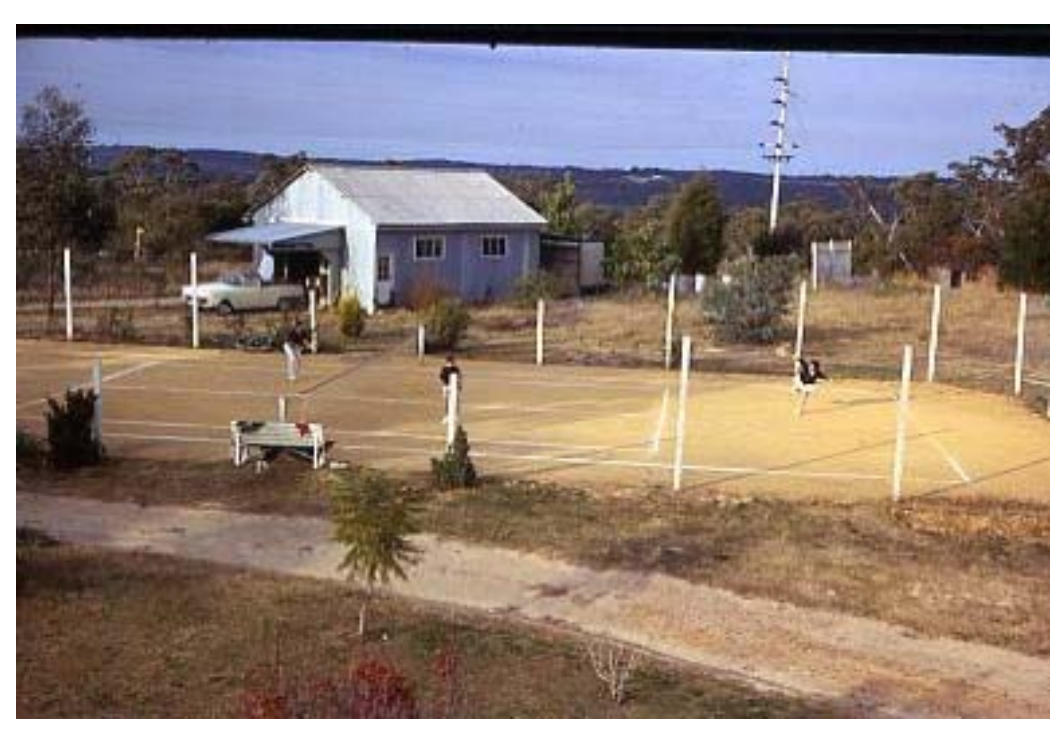

Dry Tennis Court and Lawn - Peats Ridge, circa 1968. of my childhood, along with most of the land of the working orchard, were sold off thirteen years ago, just before my father died. But a fragment of 'The Ridge' is still mine to visit. To replace the water needed for the house and for the cow pastures that now take the place of orchards and vegetable patches we have put in a bore, which periodically gets pumped up into storage tanks. Many of our neighbours similarly put in bores during the eighties and nineties to ensure a more consistent water supply than was possible with rain and spring fed dams.

Joe was sighted periodically on my trips back to the farm, working at the local 'servo' after completing his mechanics apprenticeship. He and his family had been lucky enough to own a particularly good spring on their block. News began to filter through that the Paces were selling water from their spring in barrels from the back of a tractor and that they were having trouble with the local council as a result. Growing up as I had, bottled water was almost as foreign a concept to me as the thick acidic liquid marketed under the name of 'orange juice'. Yet as I began to notice urban friends buying it regularly and tried it myself, it came to form part of the ordinary supermarket landscape.

Around a decade ago news of the Pace's success in setting up the 'Peats Ridge Springs' bottling plant on their land to fully harvest the spring reached me. Without thinking about it deeply, I was happy to hear it and to reflect on the social mobility of the migrant family behind it. When I saw Joe soon after this, although he was still working as a mechanic rather than in the family business, he was riding high. 


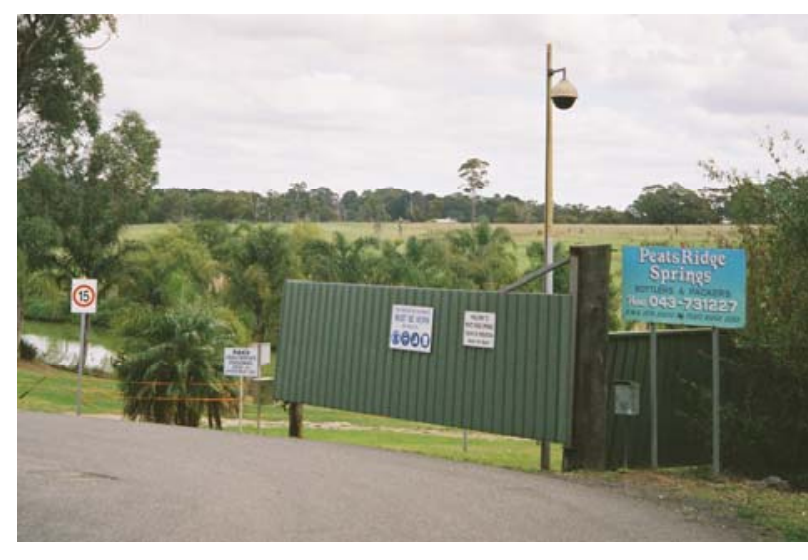

Peats Ridge Springs.

The last time I saw Joe was about seven years ago, and there was some tension between us. A city friend of mine working at the Environmental Defender's Office had told me that Peats Ridge had come to his attention because of pollution of its ground water through the leeching out of oil and petrol from the abandoned storage reservoirs of a disused petrol station. I asked Joe if this was having an impact on his family's business, and his face darkened. He denied any knowledge of the problem, whilst making clear from his body language that he could do without any stories that would detract from the squeaky clean image of their product.

Then about five years ago, out of the blue, I heard that Joe was dead, that his body been caught up somehow in the machinery of his family's bottling plant in a shocking accident. It seemed a travesty, a piece of Chaplinesque comedy, except that it was true. I live a thousand kilometres away and didn't go to the funeral, but stories that Joe had been given a police guard of honour spoke of how far he had traveled before his life was cut tragically short.

Last Christmas, I stayed once again on the remnant of my parent's land. I hadn't been to our old dam for a very long time, as it is on the land my family sold off, but one stinking hot January day we slipped down there to swim. The track down through the bush to the water was overgrown and unused looking, but the wildflowers were as beautiful as ever. When we got to the dam it was covered in slime and algae. The bush has been cleared on the opposite side where the person who now owns our adjacent neighbour's land has large greenhouses to grow flowers for the Sydney market, with fertilized water running off into the dam. We swam, but wondered afterwards about the wisdom of having done so. We did see an azure kingfisher diving repeatedly into the water, and the spring feeding the dam was 
still oozing water. Overall though, it was a dispiriting experience.

Later that day I spoke to the neighbour who bought the bulk of my family's land. He told me that he hadn't been down to the old dam for more than a decade. The bushfires of 1994 burned out the pump and parts of the irrigation line and it had not been financially possible to replace them. A new dam has been built on his land, higher up the slope, but the main source of water that he uses to run his business of growing orchids commercially is - like us - from a bore. The dam water is kept 'just in case' and he encouraged us to swim in it whenever we wanted. In the midst of a hot dry summer day his house like ours was surrounded by green grass watered from the bore. After that day we swam in his new dam every day. Surrounded by a re-growth of banksias, with a sandstone bank, water-lilies in the middle, and about eighty metres across, it was a godsend.

To drive through Peats Ridge now is to see the shiny silver tanks of small bottling plants on lots of properties beside the road and to often pass laden water tankers heading down the ridge towards Sydney and vice versa. Since 2004 water title has been legally separated from land title in NSW, making the right to extract water from a watercourse or aquifer a tradeable commodity. Many local farmers who had purchased licenses for small bores for individual farming use have sold off their water rights in perpetuity to bottling plants, who can extract the water so purchased from wherever in the local area a main bore and bottling plant is located, rather than necessarily from the land from whence the water title was

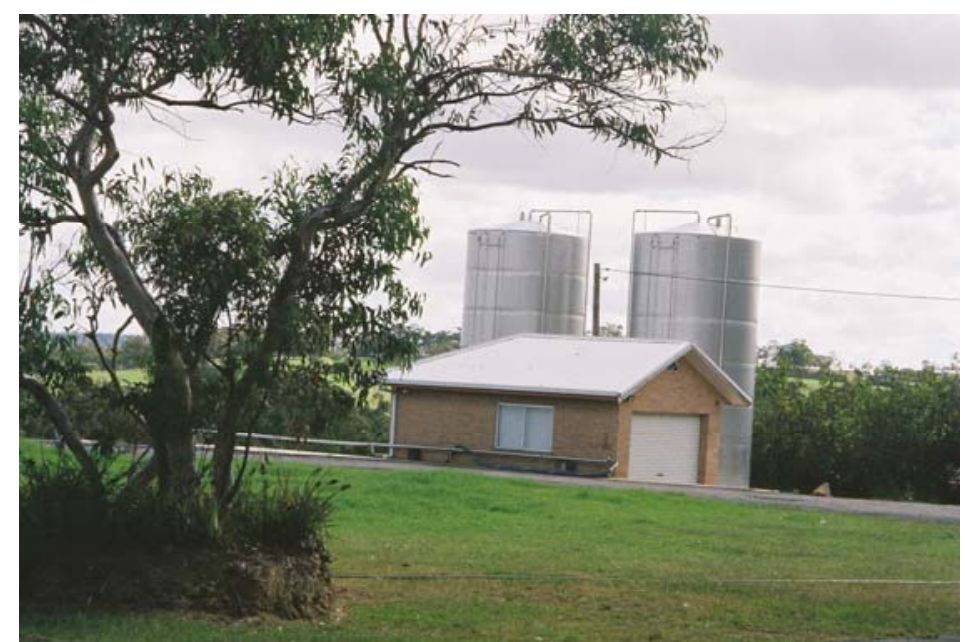

Roadside bottling plant, diseased lemon orchard in background, Peats Ridge. derived. A new form of real estate advertisement has appeared in the area, offering 'properties' (rather than the farms we always spoke of) for sale, complete with commercial water extraction licenses. Ironically, whilst these bottling plants are usually sited on one of the area's 'good springs', once it becomes a commercial 
operation the water is pumped up from groundwater far below, sometimes leaving the original spring fed creek dry.

Without being filtered in passing through layers of sandstone, the water must first be treated before it can be retailed as drinking water locally or for export. A recent study makes clear that up to a third of the groundwater samples from this region have some form of at least minor contamination, making filtration and purification of this groundwater essential, just as for the dam stored water of metropolitan water supplies. ${ }^{2}$

One of these bottling plants is at the bottom of the dirt road that leads to my family's farm. What used to be a thriving orchard of lemons beside a spring fed dam is now a patch of yellowing and neglected trees beside a shed, a shiny storage tank and a succession of silver tanker trucks that carry the water away. Not only has our neighbour's focus turned away from farming, but it has been illegal to fertilize close to where water is being bottled and without additional nutrients the sandy soil does not easily support healthy citrus trees. Now many of Peats Ridge’s farms are lying unused agriculturally: the water rights have been sold and farming without a spring is not viable and/or land owners are commuting to work in towns and a city brought much closer by the network of adjacent freeways. And so the pressure grows to subdivide land that is no longer as functional agriculturally. Some locals swear that the springs and bores are no longer as reliable or fast as once they were because of the amount of water being drawn out of the aquifer, whilst others say that it is just the natural cycle, that springs always ran faster after a wet spell and that after one of the driest periods on record them running slower is to be expected.

In mid 2003 Coca Cola purchased the 'Peats Ridge Springs' and 'Neverfail' brands and bottling plants, along with many of the other small local commercial water extraction licenses. These brands added to its overall water market share, along with the 'Mt Franklin' brand that it had previously purchased, which is the largest brand of bottled water in Australia. Globally, sales of soft drinks are down. Whilst they are still the mainstay of Coca Cola’s business, the soft drink manufacturer has been buying up water bottling rights

\footnotetext{
${ }^{2}$ Murray, J., Spratt, K., Lewis. P. \& Reimer, B. (2001) A study of groundwater quality in rural areas on the NSW Central Coast, Central Coast Public Health Unit.
} 
and plants across the world, in the US, UK, Canada and Switzerland as well as Australia. The allure of a liquid that costs almost nothing to purchase, requires no manufacture other than filtration, packaging and marketing, and carries with it a cachet of health and purity, is all too clear. Sales of bottled water have been growing exponentially globally (Inside the Bottle: An Expose of the Bottled Water Industry). As global warming and climate change begin to bite, buying bottled water is perhaps a comfort for those who can afford it in a world where such verities as always being able to turn on the tap and get fresh drinking war seem suddenly under threat. Often when I see an adult cradling a water bottle as an accompaniment to everyday life the image of a baby with a comfort milk bottle comes to mind. In India Coca-Cola has been before the courts in Kerala and forced to stop extracting water until the monsoon rains come. They had been taking out so much ground water for one of their bottling plants that the overall level of groundwater had fallen and Indian farms facing drought conditions were failing. ${ }^{3}$

This year Coca Cola Amatil applied for the right to triple the amount of water that it extracts each year from Peats Ridge Springs. Whilst the NSW State Department of Infrastructure, Planning and Natural Resources has commissioned a report that is currently being completed entitled the 'Kulnura Mangrove Groundwater Study' to enquire into issues such as whether the commercial extraction of water is leading to lower flows in springs on the mountains overall, the same department approved this application before the report was completed. The proposal was briefly held up by opposition from the Gosford City Council, whose only jurisdiction in the matter is over the buildings and the operation of the physical business required to realize the plan. In May 2005 Coca Cola Amatil initiated legal action against the Gosford City Council in the Land and Environment Court and the Council backed down. In October 2005 Coca Cola were granted a two year license to extract the 66 megalitres they were seeking. Part of the terms of this trial period is that Coca Cola themselves have been asked to monitor whether increasing the volume of water extracted has an impact on the rate of flow to their bores. Through the local papers Coca Cola has assured the local community that as their business depends upon functioning aquifers, they will do all that is required to maintain the health of the underlying hydrology.

\footnotetext{
${ }^{3}$ Clarke, T. (2005) Inside the Bottle: An Expose of the Bottled Water Industry. Ottawa: The Polaris Institute, p. 134-35.
} 


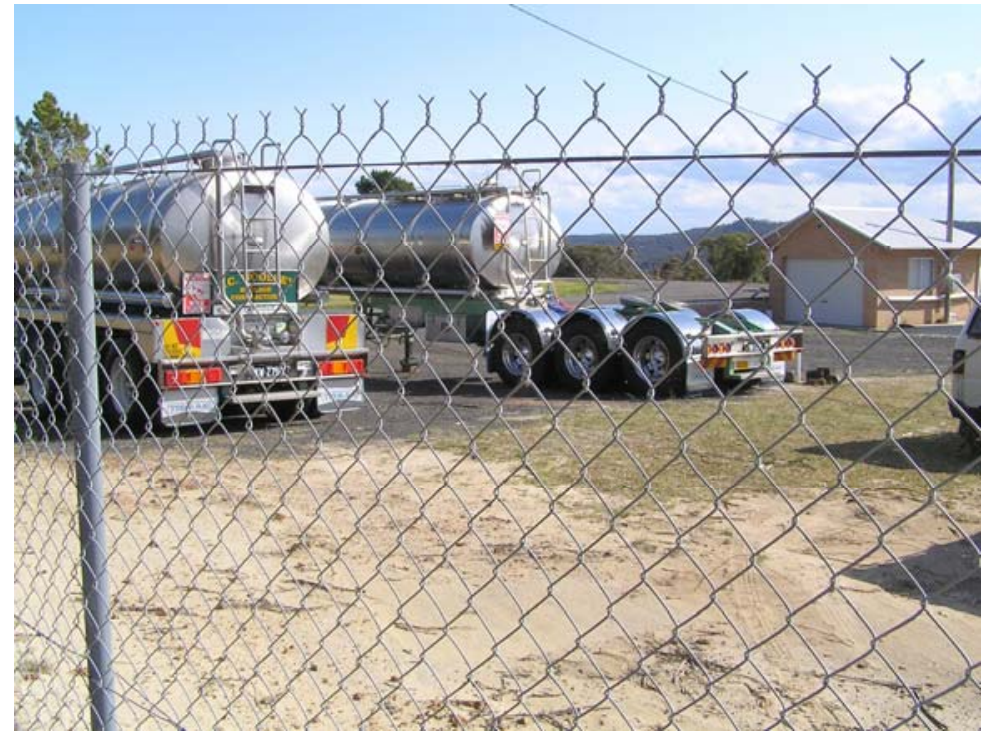

Water Tankers, Peats Ridge.

The water crisis has really hit in Sydney now. With dams running low, rainfall down and the city inexorably growing, high level water restrictions have become a daily reality in the city. Consideration of a huge investment in a sea water desalination plant is a serious part of the current public policy agenda. Laws prevent householders from filling new swimming pools with tap water unless they get a special permit and install a range of water efficient devices in their homes. Not everyone wants to commit to these constraints and so a new market for mountain water has opened up, selling water in bulk to fill the swimming pools whose spread is one of many early responses to the bite of global warming. 'Simply pure and natural aqua: Springwater delivered to your home, watertank, pool etc' reads the card of one local entrepreneur left for tourists to the district when they come to the local nursery to have Devonshire Tea. Television and radio ads exhort city householders to install pools and have them filled with 'beautiful fresh water from the Central Coast'.

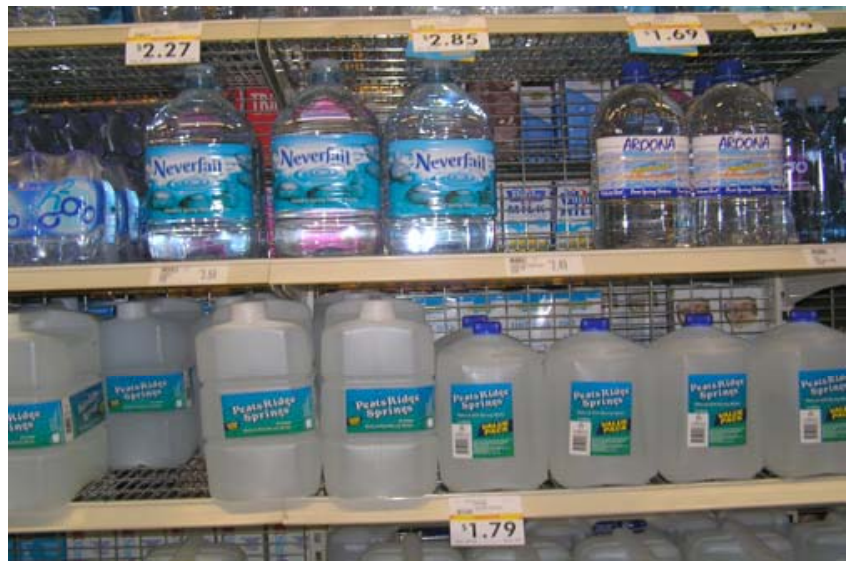

Water on Supermarket shelves, 2005. Photo: Trish FitzSimons.
I hope my dream of houses all along 'my' track was nothing more than that. That particular track is now in national park, so that bit of bush at least is hopefully 'safe'. However, the way real estate prices are running around Peats Ridge and surrounding districts, it will be hard for the next 
generation to find the economics of farming working for them, especially if the commercial extraction of groundwater and the selling off in perpetuity of water rights to particular pieces of land limits the availability of spring and bore water to supplement rainfall for farming. Chris Holstein, a member of Gosford Council, tells me that he believes that much current real estate speculation in the area is driven by the belief that it won't be long before sub division is allowed and prices can really climb to new highs. New expressways bringing the area within easy striking distance of the city are an important part of this equation.

There are no easy answers to the issues this story has raised. I live in the suburbs in a hot climate. I almost never buy bottled water and constantly pick up empty drink bottles on my morning walk to stop them being washed into our local creek as litter. But we have a swimming pool. And living in a city that has had less stringent water restrictions than Sydney, the temptation to water the lawn periodically to keep the backyard cricket pitch in shape has been irresistible. Sharing the resources of an environment has never been easy, in Australia or anywhere else. Perhaps nostalgia obscures many past complexities from me as I remember the past and look around at the present.

The point of this story is not to praise the frugality of a previous generation and denounce the profligacy of this. Living in a spring fed dam water economy there appeared no option but to carefully conserve water, and to prioritize the productive orchard getting whatever water was available. By contrast, an economy based on pumping water out of the ground gives the illusion of limitlessness, to 'Neverfail' - as the brand name of one local variety of bottled water would have it. It seems to me now that only excellent research, evidencebased public policy that requires sustainable usage by both industry and citizenry and a focus by government on communication strategies that build public support for same offers a way forward. It's hard for me to see that a large bottled water industry makes sense within such a context, especially if it means that there is less focus on maintaining high quality publicly available municipal water supplies. Having grown up to take care not to waste water as described above and as still practiced in countless rural communities in Australia today I know that water conservation can be practiced without significantly impacting upon the quality of daily life. And just as there was only really one generation that got used to an 
inexhaustible supply of plastic bags before it became clear that we needed to return to older traditions of reusing stronger bags, so it seems only collective will and financial commitment stands between us and solving current water problems. But I sniff the politics of water in the driest continent on earth, and I just know it's not going to get any easier.

\section{Acknowledgements}

I would like to acknowledge information and input to this article from Margaret Pontifex, Marigold Lawrence, Judy Callender, Robert Kemp, Janice Gray, Andrew Biro, Dan McKibbin, Clare Coase, Miranda Bueno, David FitzSimons, Chris Holstein and Danni Zuvela. Any errors of fact or interpretation however are entirely my responsibility. Vale Marigold Lawrence - may our generation adequately take up the baton.

For those who would like to know more about the issues this article raises I recommend Tony Clarke (2005) Inside the Bottle: An Expose of the Bottled Water Industry. Ottawa: The Polaris Institute, Ottawa. (Available for purchase via the internet from www.polarisinstitute.org). Although it is written from the perspective of Canada and the United States and uses North American examples, I found it to be of great relevance to giving a global context to this Australian case study.

\section{References}

Murray, J., Spratt, K., Lewis, P. \& Reimer, B. (2001) A study of groundwater quality in rural areas on the NSW Central Coast, Central Coast Public Health Unit.

Clarke, T. (2005) Inside the Bottle: An Expose of the Bottled Water Industry. Ottawa: The Polaris Institute. 